\title{
Foliar Transpiring Power: Its Estimation by Means of Standardized Hygrometric Paper Slips*.
}

\author{
Burton E. Livingston.
}

With 4 Text-figures.

Received March 30, 193\%.

\section{Introduction.}

The transpiring power of an aerially exposed plant surface may be defined as the dynamic capacity of that surface-or of the peripheral tissue behind it-to drive water vapor into the adjacent air. It represents the time rate at which water vapor would be driven out if the aerial enviromment offered no resistance to transpiration. Although any aerially exposed plant surface may be considered with respect to its transpiring power, the present paper deals only with transpiring powers of flat leaf lamina to which hygrometric paper slips may be conveniently applied by means of techniques already developed.

It is useful to compare transpiring powers of leaves with the evaporating power of a free water surface, or of a surface of wet paper, cloth, porous porcelain, ete., at some specified water temperature. Although it is convenient to distinguish between transpiring power of living leaves and evaporating power of dead leaves, paper, porcelain, etc., still the former is of course only a special case of the latter. We may employ the term transpiring power when plant (or animal) surfaces are considered, reserving the term evaporating power for all other kinds of surface.

Like other physical powers, such as the watt or the horse-power, this dynamic characteristic of a foliar surface is a measure of internal capacity for the accomplishment of work, the work here considered being the vaporization of liquid water and the driving of the resulting vapor out of the leaf. Transpiring power is to be measured or estimated as a time rate and it must always refer to a specified extent of surface, whether the area of that surface is specially considered or not.

The magnitude of the gross transpiring power of a leaf surface is, at any moment, a complex function of (a) surface area, (b) leaf tempera-

* Botanical contribution from the Johns Hopkins University no. 114. 
ture, (c) leaf structure (including more deeply seated anatomical characteristics as well as those of the two epidermises) and (d) foliar moisture condition (which may be roughly represented by water content per unit of foliar area, etc.). Area is often the most important of the several components or arguments of this function, but measurements of transpiring power per unit of area-which may be called areal transpiring power, are secured by dividing each value for gross transpiring power by the area of the surface considered.

The influence exerted on transpiring power by anatomical or material characteristics of a leaf blade may be studied without reference to leaf temperature; but it must be remembered that leaf temperature is fully as influential in the determination of transpiring power as is either tissue structure (including stomatal condition), moisture content or leaf area. In earlier papers on the use of hygrometric paper for estimating foliar transpiring power, this consideration of leaf temperature has received little or no attention, but leaf temperature is apt to fluctuate rapidly and widely and it sometimes deserves special consideration.

Under otherwise constant influential conditions, the areal transpiring power of any region of a foliar surface naturally increases with rise in foliar temperature, and conversely-in essentially the same manner as does the standard vapor pressure of pure water.

\section{Hygrometric Estimation or Measurement of Areal Foliar Transpiring Power.}

With the aid of many experimenters here and at the Desert Laboratory of the Carnegie Institution of Washington, I have been able, in the last three decades, to devise additional techniques by which the hygrometricpaper method of STAHL(18) has been rendered more quantitive, and other students of transpiration have made valuable contributions $(14,1,17,13$, $2,5,6,19,11,12,4)$. These techniques have been partially presented in earlier papers $(9,10,3,20)$ and my present purpose is to give an account of the present status of that method and of the interpretation of results secured thereby.

Early students of foliar transpiration employed tiny bell-glass desiccators charged with dry $\mathrm{CaCl}_{2}$, to show great differences between the capacities of different leaf surfaces to supply water vapor to a nearly dry and practically stagnant standard air space (See PFEFfer's Physiology of Plants, Vol. 1, p. 243). More recently Howes (8) has used a somewhat similar technique. This method is essentially similar to the one in which slips of hygrometric paper are employed, but it is less satisfactory in some ways. 
The little horn hygroscopes of Francis Darwin (7) were useful in the demonstration of pronounced differences in transpiring power, but they were not suitable for more thoroughgoing studies. For example, as the horn shaving bends away from the leaf surface it becomes more and more exposed to the conditions of the surrounding air, and the results secured thereby can represent foliar transpiring power only in part; they represent current evaporativity in part, and of course they also fail to represent the transpiration rates that might have prevailed in the absence of the instrument.

Values for areal transpiring power secured by means of hygrometric paper slips are to be considered primarily in terms of time rates of water vaporization per unit of area, as $W \mathrm{mg}$./sq.cm./sec. But comparisons may be instituted more readily if the values are expressed in terms of an unknown constant, say $W \mathrm{mg} . / \mathrm{sq} . \mathrm{cm} . / \mathrm{sec} .=u / \mathrm{sec}$., the value of $u$ being a characteristic of the hygrometric paper employed, with reference to the specified degree of color change in the latter. If the color of the standard hygrometric paper used changes from a specified bright blue to a specified pale blue with the absorption of $\mathrm{W} \mathrm{mg}$. of water vapor per square centimeter of paper, and if the time required for that color change in any test is $T$ sec., then the rate of vaporization and absorption that represents the areal transpiring power of the tested surface is $u / T$, which is proportional to the reciprocal of $T$ ' when $u$ is constant for all comparable tests. Consequently $1 / T$ is a numerical index or coefficient of areal transpiring power, which may be called $i$. The magnitude of the index $i$ for any hygrometric test is thus readily ascertained without reference either to the area of the hygrometric slip employed (which is of course the same as the area of the surface actually tested) or to the value of the constant $u$.

So long as all hygrometric slips used are essentially alike and so long as the same degree of color change is employed throughout a series of tests, any value of $i$ may be used as a unit for comparison, each of the others being expressed in terms of that unit. By this means one obtains from a number of tests a series of relative coefficients or inclices that are readily compared.

It is convenient to employ as unity for such a series the inclex value for the areal evaporating power of a standard water surface, against which hygrometric paper slips may be standardized or calibrated. That surface must be specifically defined not only with respect to its material characteristics (see below, Fig. 1) but also with respect to its temperature, for the capacity of such a surface to emit water vapor per unit of area naturally fluctuates regularly with temperature changes, just as the standard water-vapor pressure of pure water varies with temperature. 
At any temperature the areal evaporating power of the standard surface should be essentially the same as that of a free surface of pure water at the same temperature.

For example: Suppose that the test time $\left(T_{w 22^{\circ}}\right)$ for the standard water surface at $22^{\circ}$ is found to be 49 seconds; i.e., it requires 49 seconds for a standard hygrometric slip over the standard surface to change from the first to the second specified color. Then $T_{w 20^{\circ}}$ may be computed as $19.827 / 17.535 T_{w 22^{\circ}}=55$ seconds. The standard vapor pressure of pure water at $20^{\circ}$ is here taken as $17.535 \mathrm{~mm}$. of mercury column $\left(P_{20^{\circ}}\right)$ and its vapor pressure at $22^{\circ}$ is taken as $19.827\left(P_{22^{\circ}}\right)$. Suppose also that the corresponding test time $\left(T_{125^{\circ}}\right)$ for a leaf test at $25^{\circ}$ is found to be 300 seconds. The primary indices of areal evaporating power for the standard surface at $20^{\circ}\left(i_{u 20^{\circ}}\right)$ and of areal transpiring power for the tested leaf: surface at $25^{\circ}\left(i_{l 25^{\circ}}\right)$ are $1 / T_{u 20^{\circ}}$ and $1 / T_{l 25^{\circ}}$, and the corresponding relative inclices referred to $i_{w 20^{\circ}}$ are 1.00 and 0.183 ; for $1 / 300 / 1 / 55=55 / 300=0.183$. In this case the areal transpiring power of the tested leaf surface at $25^{\circ}$ is about 18 per cent. as great as is the evaporating power of the standard water surface at $20^{\circ}$. In a similar manner, $i_{125}$ may be expressed in terms of $i_{w 20^{\circ}} ; T_{w 25^{\circ}}=17.535 / 23.756 \times T_{w 20^{\circ}}=41$ seconds, and $i_{225^{\circ}} / i_{w 25^{\circ}}=$ $T_{1225^{\circ}} / T_{l 25^{\circ}}=41 / 300=0.137$; therefore the areal transpiring power of the tested leaf surface at $25^{\circ}$ is about 14 per cent. as great as is the areal evaporating power of the standard surface at $25^{\circ}$.

Tn such computations it is obviously unnecessary to ascertain the values for $i$, since these are reciprocally proportional to the corresponding values of $T$. A $T$ value for any temperature, whether for water surface or for leaf surface, may be computed for any other temperature by means of the formula $T_{t} / T_{t^{\prime}}=P_{t^{\prime}} / P_{t}$, where $P_{t^{\prime}}$ and $P_{t}$ are the standard vapor pressures of water at the temperatures $t^{\prime}$ and $t$ respectively.

Indices of areal transpiring power and evaporating power may also be expressed as the corresponding actual water-vapor pressures of the tested surfaces, in terms of millimeters of a mercury column. To do this it is necessary to suppose that the actual vapor pressure that drives water vapor from the standard water surface into the tested hygrometric slip is the standard vapor pressure of liquid water for the temperature of the standard surface. This is essentially true because the air layer between the wet paper or porous-porcelain surface of the water-surface apparatus (Fig. 1) and the hygrometric slip, when the latter is in position in that apparatus, is only $1 \mathrm{~mm}$. thick. It would be still more nearly true if that air layer were still thinner, but the 1 -mm. layer has been in use ever since this method was first introduced and it seems undesirable to consider a change in that respect. In any event, the error introduced by the $1-\mathrm{mm}$. 
layer of air is very small. Furthermore, it is of course assumed that the temperature of this air layer is the same as that of the outside air when water-surface tests are made, the air temperature being recorded as the temperature of the surface. And air temperature is generally recorded as leaf temperature when leaf tests are made, since all leaf tests are made in shade. If desirable, leaf temperature might be measured directly before each leaf test, by means of a suitable electric thermometer $(15,16)$.

For example, if the areal transpiring power of a tested leaf surface at $25^{\circ}$ is found to be 18.3 per cent. as great as the areal evaporating power of the standard water surface at $20^{\circ}$, and if the vapor pressure of the standard water surface at $20^{\circ}$ is taken as $17.535 \mathrm{~mm}$., then the vapor pressure of the leaf surface at $25^{\circ}$ is 18.3 per cent. of $17.535 \mathrm{~mm}$., or $3.209 \mathrm{~mm}$. And the vapor pressure of the tested leaf surface at $20^{\circ}$ might be computed as $17.535 / 23.756$ of $3.209 \mathrm{~mm}$., or $2.368 \mathrm{~mm}$. Such vapor-pressure indices of areal transpiring power may be employed instead of the corresponding $i$ values considered above.

\section{Preparation of Standard Hygrometric Paper Slips.}

Yniform white filter paper impregnated witl $\mathrm{CoCl}_{2}$ is the most satisfactory of all the materials thus far tried. The paper used is to be thin, and at the same time sufficiently opaque. Since $1915 \mathrm{my}$ stanclard papers have all been prepared from WIIATMaN filter paper, no. 30 (11-cm. circles), manufactured by W. and R. BALston, Ltd., of London, England. The circles are first examined by strong transmitted light and those that appear to be of uneven density are disearded. The remaining ones are essentially alike and each one is of nearly uniform density throughout.

To impregnate the selected circles with $\mathrm{CoCl}_{2}$, the standard technique employed is as follows. A $0.25-\mathrm{M}$ aqueous solution of $\mathrm{CoCl}_{2}$ ("BArer's analyzed") is made definitely acid by addition of a little $\mathrm{HCl}$. Three hundred milliliters of this solution is placed in a cylindrical glass pan about $15 \mathrm{~cm}$. in diameter and about $4 \mathrm{~cm}$. (leep), and an air-dry filter-paper circle is immersed therein, at a temperature of $21^{\circ}-25^{\circ}$. The circle remains in the solution one minute, being lifted and turned over four times, however, while the solution is continually agitated (Bone-tipped forceps are to be preferred for handling the paper circles). The circle is next transferred to a clean glass or ferrotype plate (such as is used in photography) and most of the free liquid is squeezed out by means of a photographer's squeegee roller, of rubber. After being lifted and turned over, the circle is replaced on the plate, which has been wiped dry meanwhile. It is next covered with a $15-\mathrm{cm}$. square of clean white blotting paper and the roller is again applied, with strong pressure. The circle is then placed on a 
fresh square of blotting paper in a drying oven at $100^{\circ}$, where it remains till the extreme margin begins to become blue. While most of the circle is still pink it is remored from the oven and placed between two fresh squares of blotting paper on a smooth table top, where drying is quickly completed by ironing with an electrically heated flatiron. When thoroughly dry the finished circle is bright blue, its color being somewhat more intense than that of permanent color standard no. 1, which is described below. Six or eight circles of hygrometric paper may be impregnated, one after another, with a single charge of $300 \mathrm{ml}$. of $0.25-\mathrm{I} \mathrm{CoCl}$. solution, but a firesh charge of solution should be used for the next six or eight circles to be treated.

Standard hygrometric paper thus prepared may be stored in any suitable container, protected from liquid water and dust. It may become lighter colored or even pink, on account of hygroscopic absorption of moisture from the air, but the original bright blue color returus when it is redried by heat or in a desiecator. The original color may of course bc retained if the circles are stored in a suitable desiccator. As the paper gradually absorbs moisture hygroscopically its color first comes to match color standard no. 1, then color standard no. 2, then color standard no. 3 , and finally color standard no. 4. The latter is pink.

\section{Preparation of Color Standard Papers.}

Permanently colored papers of three different intensities of blue (nos. $1-3)$ are prepared by letting $\mathrm{FeCl}_{3}$ (" $\mathrm{BAKER}_{\mathrm{AKE}}$ 's analyzed") react with $\mathrm{K}_{4} \mathrm{Fe}$ $(\mathrm{CN})_{6}$ ("BAKER's analyzed") in the filter paper itself, to produce Prussian blue $\left(\mathrm{Fe}_{4}\left[\mathrm{Fe}(\mathrm{CN})_{6}\right]_{3}\right)$, and then treating the product with eosin dye. Permanently pink paper (no. 4) is colored with eosin alone. The eosin used is marked "Eosin (Bluish blend), formerly" sold as Eosin B"'; it is manufactured by the Coleman and Bels Co., Norwood, Ohio, U.S.A. This dye is much more satisfactory than the pink madder formerly used. The concentrations of the liquids employed are as follows:--

\begin{tabular}{|c|c|c|c|c|}
\hline & $\begin{array}{c}\text { No. } 1 \\
\text { (Bright blue) }\end{array}$ & $\frac{\text { No. " - }}{\text { (Medium blue) }}$ & $\begin{array}{c}\text { No. } 3 \\
\text { (Pale blue) }\end{array}$ & $\begin{array}{l}\text { No. } t \\
\text { ( Pink) }\end{array}$ \\
\hline $\mathrm{FeCl}$ & $0.0050 \mathrm{MI}$ & $0.0030 \mathrm{~N}$ & $0.0010 \mathrm{MI}$ & - \\
\hline $\mathrm{K}_{t} \mathrm{Fe}(\mathrm{CN})_{i ;}$ & $0.0025 \mathrm{M}$ & $0.0015 \mathrm{M}$ & $0.0005 \mathrm{MT}$ & 一 \\
\hline Eosin, bluish & $\begin{array}{l}0.0 .5 \mathrm{gm} . \\
\text { per liter }\end{array}$ & $\begin{array}{l}0.0 .5 \text { gm. } \\
\text { per liter }\end{array}$ & $\begin{array}{l}0.0 \bar{g} \mathrm{gm} . \\
\text { per liter }\end{array}$ & $\begin{array}{l}0.0 \text { s gim. } \\
\text { per liter }\end{array}$ \\
\hline
\end{tabular}

For color standards nos. 1, 2 and 3, the procedure is as follows:-(a) A circle of filter paper is first dipped in clistilled water and squeegeed on a glass or ferrotype plate. It is then lifted, tumed over and returned to the plate, after the latter has been wiped dry, being then thoroughly pressed 
under a fresh square of blotting paper, by means of the rubber roller.(b) The uniformly moistened circle is next placed in $300 \mathrm{ml}$. of the requisite $\mathrm{FeCl}_{3}$ solution at $21^{\circ}-25^{\circ}$ (held in a glass pan like the one mentioned above), where it remains for one minute, being turned over four times, while the solution is continually agitated. It is then placed again on the ferrotype plate, squeegeed, lifted, turned over and returned to the plate after the latter has been wiped dry. A second fresh square of blotting paper is next laid over it and the roller is applied; it is then again turned over and again pressed with the roller, under a third fresh square of blotting paper.-(c) The moist paper circle, which is now uniformly impregnated with $\mathrm{FeCl}_{3}$, is next transferred quickly to $300 \mathrm{ml}$. of the requisite $\mathrm{K}_{4} \mathrm{Fe}(\mathrm{CN})$; solution at $21^{\circ}-25^{\circ}$ (held in a glass pan like the ones mentioned above), where it remains, with several turnings and with continual agitation, for a minute or longer, till the blue reaction is complete. It is then placed on the ferrotype plate, squeegeed, lifted, turned over and returned to the plate, after the latter has been wiped dry. A fourth fresh square of blotting paper is next laid over it and the roller: is applied; it is turned over and again pressed with the roller, under a fifth fresh square of blotting paper.-(d) The moist circle, which is now uniformly impregnated with Prussian blue, is next dipped in $300 \mathrm{ml}$. of eosin solution held in a glass pan like the ones mentioned above, after which it is promptly squeegeed on the ferrotype plate, rolled under a sixtl fresh square of blotting paper as before and placed on a seventh fresh square of blotting paper in the 100-degree oven, where it remains about 10 minutes, till its original water content is reduced by about one-half. It is finally dried thoroughly between eighth and ninth fresh blotting-paper squares, by means of an electrically heated flatiron.-Six or eight circles may be treated, one after another with $300 \mathrm{ml}$. of $\mathrm{FeCl}_{3}, \mathrm{~K}_{4} \mathrm{Fe}(\mathrm{CN})_{\text {if }}$ or eosin solution, but it is well to discard the used solution in every instance after six or eight treatments, replacing it with fresh.

To prepare the pink color-standard paper (no. 4), a circle of filter paper is brought to uniform moisture content, treated with eosin solution and then dried, the procedure followed being exactly like that just described for the blue standard excepting that steps $b$ and $c$ of that procedure are omitted.

The colors of these standard papers do not alter with changes in their hygroscopic moisture contents. Although reasonably light-fast, they should be stored in darkness, protected from dust and liquid water. As has been noted, color standard no. 1 is somewhat less intensely blue than is the standard hygrometric paper when the latter is thoroughly dry. Color standard no. 2 is of a blue color much less intense than that of no. 1. Color 
standard no. 3 is very pale blue or lavender, nearly white; it matches the color of the standard hygrometric paper just before the latter begins to appear definitely pinkish through progressive absorption of hygroscopic moisture. Color standard no. 4 matches the color of the standard hygrometric paper after the latter has become clearly pink through further absorption of moistrue.

It is readily understood that some of the various details of procedure just set forth might possibly be modified to some extent, but it is essential —or at least highly desirable-that hygrometric paper and color-standard paper should always be like those here described; otherwise results may be comparable only within their own series. Any one who prepares these papers should have samples from this laboratory for comparisons. Color standard no. 4 (pink) is usually not needed, excepting under very special eonditions.

\section{The Standard Water Surface.}

As has been said, the transpiring power of any leaf surface tested $\left(i_{l}\right)$ is to be expressed in terms of the corresponding capacity $\left(i_{w}\right)$ of a standard water surface to give off water vapor. The simplest form of standard surface consists essentially of a thoroughly wet piece of porous porcelain (or porous paper) covered with a vulcanite or hard-rubber plate $1 \mathrm{~mm}$. thick. The plate has a central circular opening 6-8 mm.

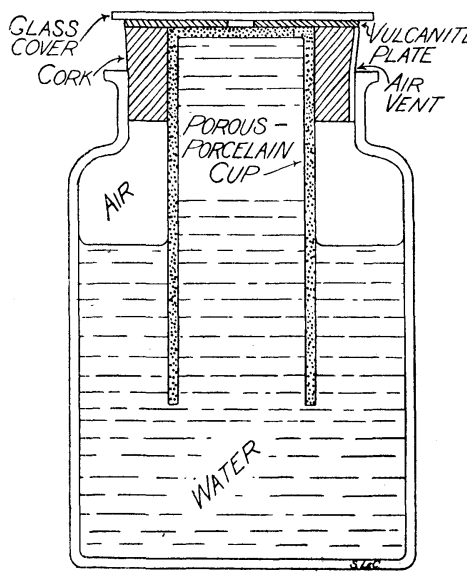

Fig. 1. Diagram showing details of construction of standard water surface. Hygrometric slip to be tested lies against glass cover, separated from wet porous-porcelain by $1-\mathrm{mm}$. air layer. in diameter. 'The form now generally used (which may be obtained from this laboratory) is shown diagrammatically in Fig. 1. A large-mouth bottle $(10.5 \mathrm{~cm}$. high, $5.7 \mathrm{~cm}$. in diameter at opening) is closed by a flat cork stopper with vertical groove for air vent. The stopper bears an inverted porous-porcelain eylinder (7.5) $\mathrm{cm}$. high and $2.5 \mathrm{~cm}$. in diameter), whose upper (closed) end is a smooth flat plate. The plane porcelain surface of that plate is even with the upper surface of the cork. A vulcanite disk $(1 \mathrm{~mm}$. thick, with a central circular hole $6 \mathrm{~mm}$. in diameter) is cemented to the cork, covering the upper surface of the latter, and that of the procelain plate excepting for the hole in the disk. An unattached clear glass plate (microscope slide) covers the vulcanite 
disk. After the bottle has been nearly filled with distilled water and the cork assembly has been set into place, the whole is inverted for a few seconds, in order to fill the cup with water, being then returned to the upright position. The flat porcelain plate, thoroughly saturated with water, gives off water vapor, like a liquid water surface, into the enclosed air layer that occupies the opening in the vulcanite disk. The glass cover is kept in place excepting when a hygrometric slip is to be inserted or removed. When not in use, the bottle should be empty and the cork assembly should be dried and kept clean. It is well to wet the procelain eylinder once, prior to the first filling, with a $1: 1000$ aqueous solution of $\mathrm{HgCl}_{2}$, which acts as antiseptic.

In using the standard water surface, it is necessary to record the temperature of the water-saturated air that is enclosed between porous plate and glass cover, but no thermometer is incorporated in this simple apparatus. Therefore the apparatus is first allowed to come to room temperature (with the glass cover in place) and room temperature is then taken as the current temperature of the enclosed air. If it were desirable, the enclosed air space might be provided with a suitable thermometer, but that would render the arrangement and its use unnecessarily complex. Surely the precision of the apparatus here described is amply adequate for the required measurements. This general method obviously involves experimental errors of several kinds, but the technique itself is already more satisfactory than is the method of sampling by which transpiring powers of leaves and whole plants are to be estimated; for of course the hygrometric slips are applied only to selected (although presumably representative) sample areas and it would not be feasible to apply them throughout a leafy plant or even throughout the whole surface of a large leaf.

\section{Leaf Clips.}

For applying a hygrometric paper slip to a leaf, a small spring clip is generally used, such as is shown in Fig. 2. This consists of a loop of

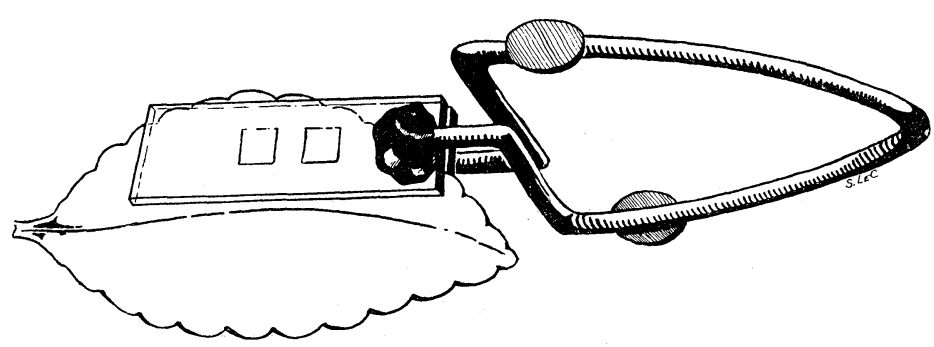

Fig. 2. Clip for applying hygrometric paper slip to leaf surface. 
hard-brass wire (about $1 \mathrm{~mm}$. in diameter) whose free ends are crossed, each end being cemented to a thin rectangular glass plate $3 \mathrm{~cm}$. long, 1.2 wide and about $1 \mathrm{~mm}$. thick. When the clip is closed on a leaf the plates lie against the two leaf surfaces, holding a paper slip in contact with one of the surfaces. The wire loop bears two small disks of brass, which facilitate manipulation of the clip between thumb and finger; pressure against: these disks opens the clip and it automatically closes when released. Of course clips of other sizes, and various other devices, may be employed for applying paper slips to plant surfaces; in this connection, see especially the techniques described by Shive and Martin (13), Meyer (12) and Blaydes (4). Clips of the form here described may be obtained from this laboratory and special ones may be made up on request.

\section{Standardization of Hygrometric Paper Slips.}

$\Lambda$ circle of hygrometric paper is cut into slips about 5 or $6 \mathrm{~mm}$. square. It is well to discard a few millimeters at the margin of the circle. The slips may be stored in a desiccator, or in a number of small desiccators, over dry $\mathrm{CaCl}_{2}$ or $\mathrm{P}_{2} \mathrm{O}_{5}$, etc. Each may be marked, for identification, by means of a small pencilled number near one corner. All slips may be tested on the standard water surface before leaf tests are begun, but if the circles of hygrometric paper are alike and if each is practically uniform throughout, only a few sample slips need to be tested. If slips are found to differ considerably as to their color reactions, their several reaction coefficients may be recorded for future use, or all but those that are essentially alike may be discarded.

To test a slip it is first thoroughly dried in a desiccator, or it may be dried in an oven or over a heated surface-as of a lighted incandescent electric lamp, an inverted electrically heated flatiron, a gas or electrically heated hot plate, the top of a portable acetylene (carbide) lamp, etc. In an emergency a candle flame or the flame of a kerosene lamp may be used. To heat a slip, it is held by means of forceps, in a position where the full blue color will be attained in a minute or less, but too intense heat is of course to be avoided. Heated slips should be cooled in a desiccator, for they should always be at air temperature when tested, or when applied to a leaf. A dry (bright blue) slip is quickly laid-marked side down-over the circular opening in the vulcanite plate of the standard water surface, it is covered with the glass plate, and the time required for the desired degree of color change $\left(T_{w}\right)$ is recorded. The water surface should be at air temperature $(t)$ which is also recorded. It is of course very important that the porcelain plate and the paper clip should be at the same known temperature. 
To show degrees of color change, a $6 \mathrm{~mm}$. scuare of color-standard paper no. 1 (or no. 2) and one of color-standard paper no. 3 (or no. 2 or no. 4) should have been previously attached (by a tiny bit of adhesive such as flour paste, at one corner of each slip) to the under side of the glass cover near its center, the two being $6 \mathrm{~mm}$. apart. The plate is so placed over the hygrometric slip to be tested that the latter is clearly seen through the glass, lying between the two attached color-standard slips.

The water-surface time $\left(T_{u t}\right)$ at temperature $t$ is the number of seconds elapsing between (a) the time when the color of the hygrometric slip matches that of color standard no. 1 (or no. 2) and (b) the later time when it matches the color of the other standard used. (A stop-watch is used for timing.) Of course each test should be repeated several times, the results being averaged to give $T_{\text {ut } t}$.

Slips may be standardized for the several different ranges of color change, since it may be desirable to employ different ranges when leaf tests are made; i.e., $T_{\text {ut }}$ may be found for color ranges from no. 1 to no: 2, from no. 1 to no. 3, from no. 1 to no. 4, ete. These values may be designated as $T_{u t(1-2)}, T_{u t(1-3)}$, etc. The range from color no. 1 to color no. 3 (from bright blue to pale biue) is generally most useful. The pink color should never be used excepting for special reasons, since the capacity of a hygrometric slip to absorb water vapor is very small after the paleblue color has been passed.

The value of $T_{u}$ for any temperature $\left(t^{\prime}\right)$ may be computed from its value for the temperature of observation $(t)$, since $T_{w}$ has been shown (10) to vary with temperature inversely as does the standard vapor pressure of water $(P)$ :

$$
T_{w t^{\prime}(1-3)}=T_{u t(1-3)} \times \frac{P_{t}}{P_{t^{\prime}}} .
$$

'Thus, if a slip on the standard water surface at $24.4^{\circ}(t)$ changes from color no. 1 to eolor no. 3 in $42 \mathrm{sec} .\left(T_{\text {wi(1-3) }}\right)$, its time for the same color change at $20^{\circ}\left(T_{w t^{\prime}(1-3)}\right)$ is $42 \times 22.922 / 17.535$, or about $55 \mathrm{sec}$. (Vaporpressure values used in this paper are expressed as millimeters of mercury column and are taken from page 1228 of HoDqMaN's Handbook of Chemistry and Physies, 19th edition; Chem. Rubber Publ. Co., Cleveland, Ohio; 1934). It is clear that the height of the air space between wet porcelain plate and hygrometric slip is a very important characteristic of the standard water surface, for the water vapor emanating from the plate must pass across that space before reaching the hygrometric slip. As has been said that height is $1 \mathrm{~mm}$. in my standard apparatus. For most comparisons barometric pressure may safely be left out of account.

Within a range of variation of plus or minus less than 10 per cent., 
my standard hygrometric paper and standard-color papers are characterized by the following test times for the standard water surface at $20^{\circ}$ :$T_{w(1-2)}, 30$ sec.; $T_{w(1-3)}, 55$ sec.; $T_{w(1-4)}, 75$ sec.; $T_{w(2-3)}, 25$ sec.; $T_{w(2-4)}, 45$ sec.; $T_{w(3-4)}, 20$ sec.

The two color-standard slips for the water-surface tests may be held in place on the under side of the glass cover plate by covering them with a second plate of very thin glass (such as that used for covers on microscope slides), this being attached to the cover plate by means of suitable cement (e.g., Canada balsam) applied at the corners. Slips of all four color. standards may be so arranged (with or without thin cover glass) as to form a hollow square, within which the hygrometric slip undergoing test appears when the cover plate is applied. Or the tripartite slips described below may be used for all tests, each hygrometric slip carrying with it two color-standard slips. Additional modifications of the standardization technique here described will probably suggest themselves to those who are familiar with the principles of this method. Some modifications have been described in the earlier literature.

\section{Leaf Tests.}

One plate of each glass clip used for leaf tests is generally provided, on its inner face, with color-standard slips, in the manner just described for the cover plate of the standard water surface (as is indicated by the two squares in Fig. 2), so that a hygrometric slip in contact with the leaf may be seen through the glass, lying between the two color-standard slips. A thin cover glass may be attached, to cover and protect the color-standard slips. Four of the latter may be used, arranged to form a hollow square, with or without cover. It is usually best to apply but a single hygrometric slip with each clip, the second glass plate of the clip being left vacant, serving only to hold the leaf against the first plate and against the hygrometric slip.

The leaf tested is generally supposed to have the same temperature as the surrounding air; but, when desirable, its actual temperature may be approximately measured just prior to the hygrometric test, with a suitable electric thermometer $(15,16)$. During the period of a hygrometric test the leaf must not receive direct sunshine; otherwise the part tested might become excessively heated. In any case, the estimated leaf temperature is recorded.

To make a leaf test, a desiccator-dried (bright blue) hygrometric slip is quickly placed in position in a glass clip and the latter is allowed to close. The clip is then brought to the leaf to be tested, with the glass plates horizontal. The clip is next opened (with paper slips resting on the 
upper face of the lower plate) and applied to the leaf, which is temporarily held nearly horizontal. (See Fig. 2.) Thus the three slips come to lie side by side on the physically lower surface of the leaf, and water vapor from the surrounding air is practically excluded. According to the position in which the leaf is held as the charged clip is applied, and according. to the position of the leaf within the clip, the paper slip may be applied to either of the two morphological surfaces of a leaf and to any region thereof. Excepting in special studies, the leaf is to remain attached to the plant. Clips of the form described above may generally be allowed to hang on the leaves, but extra supports may be easily arranged when needed.

The usefulness of this general method depends largely, of course, on the ability of the operator to fix upon the exact moment when the color of the hygrometric slip just matches the color of a standard-color slip. After some practice, most persons become expert in this, but some eyes appear to be unsuited to this sort of study. A stop-watch is essential for all these tests. When the surface tested is so uneven as to permit considerable gas interchange between the surrounding air and the hygrometric slip, the color of the slip may change more or less rapidly at the margin than in the middle region; it is therefore best always to confine attention to the middle region. When the surrounding air is very dry (as in arid climates) slip margins may change color less rapidly than their middle portions, but in humid climates the margin may change somewhat more rapidly than the middle. As in other delicate operations, practice is usually necessary before a tyro may become an expert.

Instead of employing color-standard slips attached to the under side of the glass cover of the apparatus and to the leaf clips, as described above, it is very convenient to use tripartite hygrometric slips for all tests. These may be prepared by the experimenter, or they may be obtained from this laboratory. Each standard tripartite slip (about $5 \mathrm{~mm}$. wide and $12 \mathrm{~mm}$. long $)$ is made up of a rectangular middle part $(4 \mathrm{~mm} . \times 5 \mathrm{~mm}$. $)$ of standard hygrometric paper to which is attached, one on either side, two like rectangles of standard color paper, one of the latter being bright blue while the other is pale blue. A very narrow strip of adhesive black silk cloth (court plaster) along each of the long margins of a tripartite slip holds the three parts together, edge to edge. These little devices are handled as single slips, being alway's observed from the side which is without black margins. A time observation is begun when the color of the middle part matches that of the bright blue part and it ends when the color of the middle part matches that of the pale blue part.

The leaf-test time $\left(T_{1}\right)$ is the number of seconds elapsing between (a) the time when the color of the hygrometric slip matches that of color stand- 
ard no. 1 (or perhaps no. 2 , if the air is very moist) and (b) the time when it matches the color of standard no. 2 (or no. 3). For any specified degree of color change we may let the symbols $T_{w t}$ and $T_{u t}$ ' represent the test times for the standard water surface at the temperatures $t$ and $t^{\prime}$, and the symbols $T^{\prime}{ }_{l t}$ and $T_{l l}$ ' may represent the corresponding test times for the leaf surface at those temperatures, while $P_{t}$ and $P_{t^{\prime}}$ may represent the vapor tensions of water at the same temperatures. Then these values have the following relations :-

$$
T_{u t} / T_{w t^{\prime}}=T_{l t} / T_{l t^{\prime}}=P_{t^{\prime}} / P_{t} .
$$

Also $T_{u t} / T_{l l}=T_{u t^{\prime}} / T_{t t^{\prime}}=c$, where $c$ is the index of areal transpiring power of the leaf surface tested, expressed in terms of the areal evaporating power of the standard water surface when leaf temperature and water-surface temperature are taken to be alike. If, however, the influence of fluctuating leaf temperature is to be taken into account in the index of areal transpiring power, then $T_{u t} / T^{\prime} \iota^{\prime}=k$. Thus differences between $c$ values are considered as due wholly to anatomical and material differences, such as may develop and alter within a single day (like stomatal differences and those of foliar moisture content), while differences between $k$ values are due partially to anatomical and material differences and partially to differences in foliar temperature. Indices for the upper leaf surface may be designated by $c$ and $k$, those for the lower surface by $c^{\prime}$ and $k^{\prime}$, while those for both surfaces taken together may be $C$ (which is $\left(c+c^{\prime}\right) / 2$ ) and

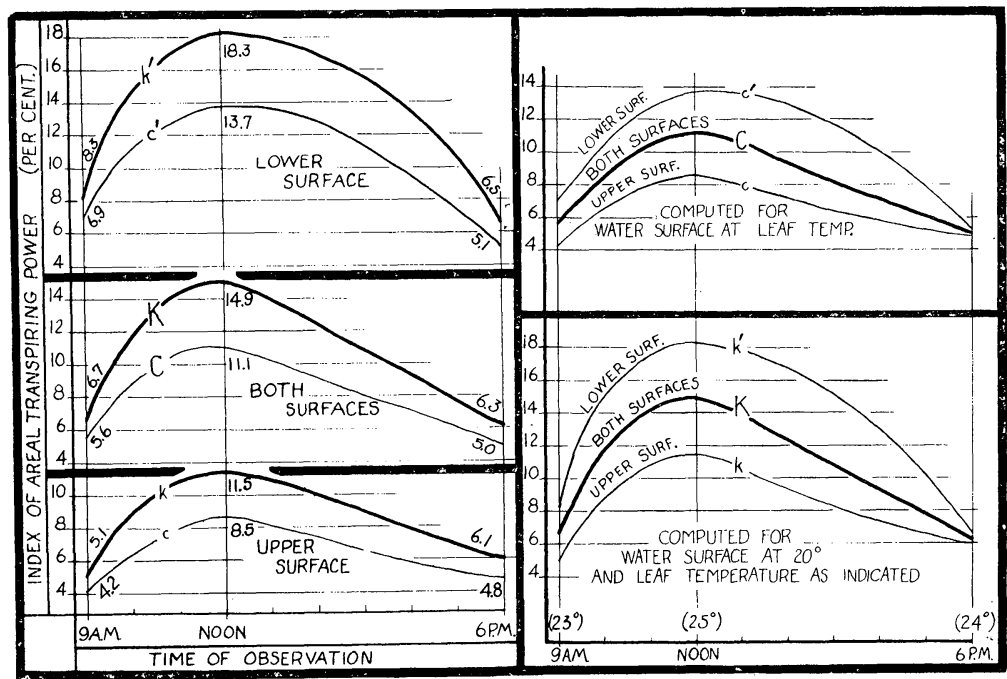

Fig. 3. Time graphs of areal transpiring powers of leaves of Colcus plant in diffuse light. $K, k$ and $k^{\prime}$ represent transpiring powers as percentages of evaporating power of water surface at $20^{\circ} ; C, c$ and $c^{\prime}$ represent corresponding percentages of evaporating powers of water surface at leaf temperatures. 
Table 1. Data from Coleus plant in diffuse light.

\begin{tabular}{|c|c|c|c|}
\hline Tour of day & 9 a. $\mathrm{m}$. & Noon & $6 \mathrm{p.m}$. \\
\hline Leaf temperature, $t^{\prime}$ & $23^{\circ}$ & $25^{\circ}$ & $24^{\circ}$ \\
\hline Vapor pressure of $\mathrm{H}_{2} \mathrm{O}, P_{t^{\prime}}$ & $P_{23 \circ}=21.068 \mathrm{~mm}$. & $P_{25^{\circ}}=23756 \mathrm{~mm}$ & $P_{24^{\circ}}=22.377 \mathrm{~mm}$ \\
\hline $\begin{array}{l}\text { Water-surface time, } T_{w t^{\prime}} \\
\text { (c } \operatorname{mputed} \text { from } T_{w: 0^{\circ}=55 \text { sec.) }}\end{array}$ & $T_{w 23^{\circ}}=46$ see. & $T_{w 25^{2}}=41 \mathrm{~s} 2 \mathrm{c}$ & $T_{w 24^{\circ}}=43$ see. \\
\hline $\begin{array}{c}\text { Upper leaf surface:- } \\
\qquad T_{l t^{\prime}} \text { (observed) }\end{array}$ & $T_{l \underline{2} 3^{\circ}}=1080 \mathrm{sec}$. & $T_{l 25}=480$ sec. & $T_{l 24^{\circ}}=900 \mathrm{sec}$ \\
\hline$T_{l: 0^{2}}$ (computed) & 1298 sec. & $650 \mathrm{sec}$. & 1149 sec. \\
\hline$c=\frac{T_{v t^{\prime}}}{T_{l t^{\prime}}}=\frac{T_{v \varepsilon 0^{\circ}}}{T_{l=0^{\prime}}}$ & 0.042 & 0.085 & 0.048 \\
\hline$k=\frac{T_{w 20^{3}}}{T_{2 t^{\prime}}}$ & 0.051 & 0.115 & 0.061 \\
\hline Foliar vapor pressure, $P i t$, & $P_{l^{2} 3^{\circ}}=0.894 \mathrm{~mm}$. & $P_{l: 5^{\circ}}=2.017 \mathrm{~mm}$ & $P_{l 24^{\circ}}=1.070 \mathrm{~mm}$ \\
\hline $\begin{array}{l}\text { Lower leaf surface:- } \\
T^{\prime}{ }_{\iota t} \text {, (observed) }\end{array}$ & $T^{\prime} l_{23}=660 \mathrm{sec}$ & $T^{\prime}{ }_{l 25^{\prime}}=300$ sec. & $T^{\prime} t 24^{\circ}=840 \mathrm{sec}$ \\
\hline$T_{l=0}^{\prime}$ (computed) & 793 sec. & 401 sec. & 1071 sec. \\
\hline$c^{\prime}$ & 0.069 & 0.137 & 0.051 \\
\hline$k^{\prime}$ & 0.083 & 0.183 & 0.065 \\
\hline Foliar vapor pressure, $P^{\prime}{ }_{l t^{\prime}}$ & $P^{\prime} l 23^{\circ}=1.455 \mathrm{~mm}$ & $P=5.209 \mathrm{~mm}$ & $P^{\prime}{ }^{2} 24^{\circ}=2.140 \mathrm{~mm}$. \\
\hline $\begin{array}{l}\text { Ratio, lower to upper leaf } \\
\text { surface, } c^{\prime} / c\end{array}$ & 1.64 & 1.61 & 1.06 \\
\hline $\begin{array}{l}\text { Both leaf surfaces:- } \\
\qquad C=\frac{c+c^{\prime}}{2}\end{array}$ & 0.056 & 0.111 & $0.0 \tilde{0} 0$ \\
\hline$K=\frac{k+k^{\prime}}{2}$ & 0.067 & 仓.149 & 0.063 \\
\hline $\begin{array}{l}\text { Foliar vapor } \\
\text { pressure, }\end{array} \frac{P_{l t^{\prime}}+P^{\prime} l t^{\prime}}{2}$ & $1.175 \mathrm{~mm}$. & $2.613 \mathrm{~mm}$. & $1.605 \mathrm{~mm}$ \\
\hline
\end{tabular}

$K$ (which is $\left.\left(k+k^{\prime}\right) / 2\right)$. To express these indices as percentages, each is of course to be multiplied by 100 .

\section{Examples.}

The following examples may serve to illustrate various details of this method for estimating foliar transpiring power.

Example 1.-The numerical data presented in Table 1 and shown by 
the graphs of Fig. 3 refer to a small greenhouse-grown plant of hybrid Coleus, without red coloration. The plant was in the diffuse light of a laboratory room at Baltimore, and these tests were made on March 4. The color change employed was always from color no. 1 (bright blue) to color no. 3 (pale blue). Values for only 9 a.m., noon and 6 p.m. are given. Air temperatures (taken as leaf temperatures) were $23^{\circ}, 25^{\circ}$ and $24^{\circ}$, respectively. In the water-surface apparatus the hygrometric slips used changed from bright blue to pale blue in 55 seconds at $20^{\circ}$ (for which the vapor tension of water is $17.535 \mathrm{~mm}$.) ; i.e., $T_{w: 20^{\circ}}=55$ sec., while $T_{w 23^{\circ}}, T_{w 25^{\circ}}$, and $T_{w 24^{\circ}}$ are computed to be 46 sec., 41 sec. and 43 sec., respectively.

At 9 a.m. the areal transpiring power of the upper surface of the leaves, as influenced only by anatomical and material characteristics $(c)$, was 4.2 per cent. as great as the evaporating power of the standard water surface at the same temperature; at noon this percentage was 8.5 and at 6 p.m. it was 4.8. For the lower leaf surface the corresponding percentages $\left(c^{\prime}\right)$ are $6.9,13.7$ and 5.1. At 6 p.m., when stomata were presumably closed, this index of areal transpiring power was essentially the same for the two leaf surfaces $(4.8,5.1$ per cent.), but for the upper (non-stomatal) surface it was 77 per cent. greater at noon than at 6 p.m., while for the lower surface it was 169 per cent. greater at noon than at 6 p.m.

When the influence of leaf temperature is included by computing all index values in terms of the constant value for the water surface at $20^{\circ}$, the resulting percentage coefficients are $(k)$ 5.1, 11.5, 6.1 for the upper leaf surface and $\left(k^{\prime}\right) 8.3,18.3,6.5$ for the lower. Of course this value also is essentially the same for both surfaces at 6 p.m.; but this method of computation shows that the actual areal transpiring power of the upper surface was 89 per cent. (instead of 77 per cent.) greater, while that of the lower surface was 182 per cent. (instead of 169 per cent.) greater at noon than at 6 p.m. These differences between the results secured by neglecting temperature influence and by including it in the computation are naturally due to the fact that leaf temperature was a clegree higher at noon than at 6 p.m.

The computed foliar vapor pressures shown in Table 1 are proportional to the index values $\left(k, k^{\prime}, K\right)$ computed to include temperature influence. They represent a static characteristic of the leaf surface but their values are taken to be proportional to the dynamic characteristic, areal transpiring power. The greatest foliar vapor pressure shown $(3.209 \mathrm{~mm}$., for lower leaf surface at noon, at $25^{\circ}$ ) is equivalent to the vapor pressure of pure ice at $-4.3^{\circ}$, and the smallest $\left(0.894 \mathrm{~mm}\right.$., for upper surface at 9 a.m., at $23^{\circ}$ ) is equivalent to the vapor pressure of pure ice at $-26^{\circ}$.

Example 2.- The data presented in Table 2 and in the graphs of Fig. 4 
are taken from Trelease and Livingston's Table 1 (20). They refer to the lower surfaces of leaves of Zebrina pendula, in one of the greenhouse rooms of this laboratory, and the observations were made on June 10 . The test time for the hygrometric slips used, when applied to the standard water surface, was 28.2 seconds at $22.5^{\circ}$, 32.9 seconds at $20^{\circ}$.

As in the preceding example, each value of $c^{\prime}$ represents areal transpiring power expressed in terms of. the evaporating power of the standard water surface at the leaf temperature, and each value of $k^{\prime}$ represents areal transpiring power in terms of

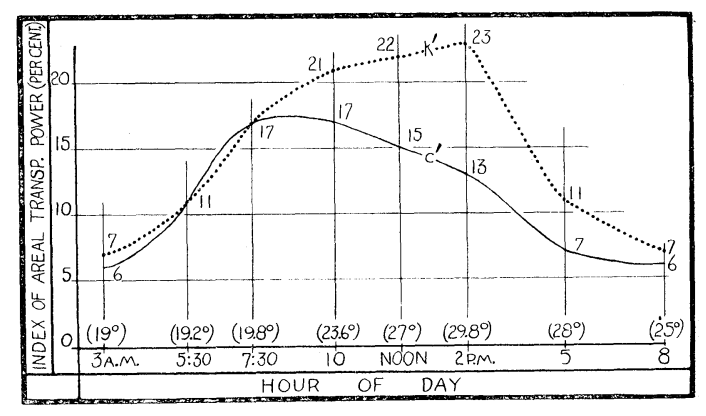

Fig. 4. Time graphs of areal transpiring powers of lower surfaces of leaves of Zebrina plant in diffuse light. Ordinates are pereentages of evaporating power of water surface at $20^{\circ}\left(c^{\prime}\right)$ and at leaf temperatures $\left(k^{\prime}\right)$. the evaporating power of the standard surface at $20^{\circ}$. The high leaf temperatures of the middle of the day are seen to have been markedly effective to increase foliar vapor pressure and the dynamic capacity of the leaves to emit water vapor; although transpiring power based only on the non-temperature features of the leaves $\left(c^{\prime}\right)$ attained its maximum about $7: 30-10$ a.m., the maximal value of $k^{\prime}$ was not attained till 2 p.m.

Table 2. Data from lower leaf surface of Zebrina pendula.

\begin{tabular}{|c|c|c|c|c|c|c|c|c|}
\hline Hour of day & $3 \mathrm{a} . \mathrm{m}$. & $5: 30$ & $7: 30$ & $10: 00$ & Noon & $2: 00$ & $5: 00$ & 8:00 p.m. \\
\hline Leaf temp., $t^{\prime}$ & $19^{\circ}$ & $19.2^{\circ}$ & $19.8^{\circ}$ & $23.6^{\circ}$ & $27^{\circ}$ & $29.8^{\circ}$ & $28^{\circ}$ & $25^{\circ}$ \\
\hline $\begin{array}{l}\text { Vap. pressure of } \\
\mathrm{H}_{2} \mathrm{O}, \mathrm{Pt}^{\prime} \text { (mm.) }\end{array}$ & 16.48 & 16.69 & 17.32 & 21.85 & 26.74 & 31.46 & 28.35 & 23.76 \\
\hline$T_{l t^{\prime}}$ (observed), sec. & $57 \tilde{5}$ & 311. & 195 & 157 & 148 & 142 & 291 & 532 \\
\hline$T_{l 200^{\prime}(\mathrm{computed}), \text { sec }}$ & 536 & 296 & 193 & 196 & 225 & 254 & 470 & 720 \\
\hline$c^{\prime}$ & 0.06 & 0.11 & 0.17 & 0.17 & 0.15 & 0.13 & 0.07 & 0.06 \\
\hline$k^{\prime}$ & 0.07 & 0.11 & 0.17 & 0.21 & 0.22 & 0.23 & 0.11 & 0.07 \\
\hline $\begin{array}{l}\text { Foliar vap. pres., } \\
P_{l t^{\prime}}(\mathrm{mm} .)\end{array}$ & 1.23 & 1.93 & 2.98 & 3.68 & 3.86 & 4.03 & 1.93 & 1.05 \\
\hline
\end{tabular}

\section{Abstract.}

A brief general discussion of the general meaning of transpiring 
power is followed by a detailed account of the present status of the method of $\mathrm{CoCl}_{2}$ paper for estimating foliar transpiring power. Full directions are given for preparing both standard hygrometric paper and the four standard color papers that are employed in the timing of the color changes that indicate rates of water-vapor absorption by the hygrometric slips. A standard water-surface apparatus is described; also a tripartite slip, which consists of a hygrometric slip and two color-standard slips combined. Procedures of computation are also presented, by means of which results secured with this method may be interpreted. Finally, some examples are given from experiments, to illustrate applications of the method.

\section{Laboratory of Plant Physiology, The Johns Ilopkins} University, Baltimore, Md., U.S.A.

\section{Literature Cited.}

1. BAкKe, A. L. 1914. Studies on the transpiring power of plants as indicated by the method of standardized hygrometric paper. Jour. Ecol. 2: 145-173.

2. - 1918. Determination of wilting. Bot. Gaz. 66: 81-116.

3. _-_- and B.E. Livingston. 1916. Further studies on foliar transpiring power in plants. Physiol. Res. 2: 51-71.

4. Braydes, G. W. 1928. A survey of rate of water loss from leaves. Ohio Jour. Sci. 28 : $99-118$.

5. CRIBbs, James E. 1919. Ecology of Tilia americana. Comparative studies of the foliar transpiring power. I. Bot. Gaz. 68: 262-286.

6. _- 1921. Same title, II. Ibid. 71: 289-313.

7. Darwin, F. 1898. Observations on stomata. Proc. Roy. Soc. London B, 63: 413417.--Idem, same title, Phil. Trans. Roy. Soc. London B, 190: 531-621.

8. Howes, F. 1923. A new calcium-chloride method of measuring the resistance of water loss in leaves. Mem. Bot. Surv. S. Africa 5: 23-33.

9. Livingston, Burton E. 1913. The resistance offered by leaves to transpirational water loss. Plant World 16: 1-35.

10. - and EDith B. Sirkeve. 1916. Improvements in the method for determining the transpiring power of plant surfaces of liygrometric paper. Plant World 19: $287-309$.

11. Meginnis, Helen A., and W. B. MCDoughll. 1923. A comparison of the transpiration rates of corn and certain common weeds. Trans. Illinois State Acad. Sei. 16: $82-88$.

12. Meyer, Bernard S. 1927. Studies on physical properties of leaves and leaf surfaces. Ohio Jour. Sci. 27 : 263-288.

13. Shive, J. W., and W. H. Martin. 1917. The effect of surface films of Bordeaux mixture on the foliar transpiring power of tomato plants. Plant World 20: $67-86$.

14. Shreve, Edith B. 1914. The daily march of transpiration in a desert perennial. Carnegie Inst. Washington Publ. 194.

15. - 1919. A thermo-electrical method for the determination of leaf temperature. Plant World 22: 100-104.

16. - 1919. The rôle of temperature in the determination of the transpiring power of leaves by hygrometric paper. Plant World 22: 172-180. 
17. SHreve, Forrest. 1916. The transpiring power of plants as influenced by differences of altitude and habitat. Seience $43: 363$.

18. Stant, E. 1894. Einige Versuehe über Transpiration and Assimilation. Bot. Zeitg. 52: 117-146.

19. Trelease, S. F. 1922. Foliar transpiring power of the coconut. Philippine Jour. Sci. 20 : $167-176$.

20. _- and 13. E. Livingston. 1916. The daily mareh of transpiring power as indieated by the porometer and by standardized hygrometrie paper. Jour. Ecol. 4: $1-14$.

\title{
A List of Chromosome Numbers in Angiospermous Plants, III.
}

\author{
By
}

\section{Toranosuke Sugiura.}

Received March 30, 193\%.

In the present paper the meiotic numbers of chromosomes recently examined in 48 species with one variety in 32 genera belonging to 21 families are added to the list of the writer's countings of chromosomes of the angiospermous plants which have already been reported in the previous papers (Sugiura, 1928, 1931, 1936a, b, 1937). The division of the pollen mother cells in all plants here listed takes place by the furrowing process.

The more detailed karyological descriptions together with illustrations will be published later.

The technique employed in the present work and the literature are to be referred to the previous paper (SUGiura, 1937).

Table 1.

\begin{tabular}{|c|c|c|c|}
\hline Plant Names. & $\mathrm{n}$ & Plant Names. & $n$ \\
\hline Compositate & & Rubiaceae & \\
\hline Cosmos sulphureus & 12 & Crucianella stylosa & 9 \\
\hline Campanulaceate & & & \\
\hline Lobelia Cliffortiana & 7 & Acanthaleease & \\
\hline I. inflata & 8 & Acanthus spinosus & 56 \\
\hline L. Richarilsonii & 21 & Dicliptera resupinata & 20 \\
\hline L. tenuior & 9 & Ruellia amoena & 18 \\
\hline Campanula abietina & 34 & R. Dipteracanthus & 18 \\
\hline C. garganica & 34 & S*rophulariaceae & \\
\hline C. Rapunculus & 51 & Hebenstreitia dentata & 7 \\
\hline
\end{tabular}

